Bryn Mawr College

Scholarship, Research, and Creative Work at Bryn Mawr

College

Sociology Faculty Research and Scholarship

Sociology

2017

\title{
Psychological adjustment after breast cancer: a systematic review of longitudinal studies
}

Tânia Brandão

Marc S. Schulz

Bryn Mawr College, mschulz@brynmawr.edu

Paula Mena Matos

Let us know how access to this document benefits you.

Follow this and additional works at: http://repository.brynmawr.edu/soc_pubs

Part of the Sociology Commons

\section{Custom Citation}

Brandão, Schulz, and Matos 2017. "Psychological adjustment after breast cancer: a systematic review of longitudinal studies." PsychoOncology 26.7: 917-926.

This paper is posted at Scholarship, Research, and Creative Work at Bryn Mawr College. http://repository.brynmawr.edu/soc_pubs/14

For more information, please contact repository@brynmawr.edu. 
Psychological adjustment after breast cancer: A systematic review of longitudinal studies

Tânia Brandão

Faculty of Psychology and Education Sciences, University of Porto, Portugal Center for Psychology at University of Porto

Marc S. Schulz

Department of Psychology, Bryn Mawr College, Pennsylvania, USA

Paula Mena Matos*

Faculty of Psychology and Education Sciences, University of Porto, Portugal

Center for Psychology at University of Porto

* Corresponding author contact information:

Paula Mena Matos

Rua Alfredo Allen

4200-135 Porto

Portugal

Telephone number +351226079700

Fax +351226079 725

Email: pmmatos@fpce.up.pt

Funding for this study was provided by a PhD Scholarship from the Portuguese Foundation for Science and Technology (FCT) granted to the first author (SFRH/BD/84436/2012). 


\title{
Psychological adjustment after breast cancer: A systematic review of longitudinal studies
}

\begin{abstract}
Objectives: Breast cancer (BC) can be a traumatic and stressful experience for women but there are wide-ranging differences in the ways in which women respond and adapt to BC. This systematic review examines which sociodemographic, disease-related, and psychosocial factors near diagnosis predict later psychological adjustment to BC.
\end{abstract}

Methods: Database searches were conducted in nine different health-related databases from 2000 to December 2015 using relevant search terms. Full-text, peer-reviewed articles in English that analyzed potential predictors of psychological adjustment in longitudinal studies were considered for inclusion.

Results: Of 1780 abstracts 41 studies fulfilled inclusion criteria. Consistent sociodemographic and disease-related variables predictors of adjustment were income, fatigue, cancer stage, and physical functioning. Psychosocial factors, particularly optimism and trait-anxiety, as well as perceived social support, coping strategies, and initial levels of psychological functioning were found to be predictive of later depressive and anxiety symptoms, psychological distress, and quality of life for women with $\mathrm{BC}$, in predictable ways. Other psychosocial variables, such as cognitive and body image factors, predicted psychological adjustment but were explored only by a few studies.

Conclusions: The majority of studies showed a significant relationship between psychosocial factors and psychological adjustment. These results point to specific sociodemographic, disease-related, and psychosocial factors that can help to identify women at the time of diagnosis who are at risk for long-term psychological challenges so they can be referred for psychological support that targets their specific needs and can improve their quality of life and mood, and decrease indicators of anxiety, depression and psychological distress.

Keywords: breast cancer, psychological adjustment, longitudinal studies, systematic review, oncology 


\section{Background}

The extension of survival rates as well as the conceptualization of cancer as a chronic disease make clear the importance of addressing how patients adjust to cancer and identifying which factors can help patients to thrive. The concept of psychological adjustment is complex and is not clearly defined in the literature. Traditionally, psychological adjustment to illness was described as the absence of a psychological disorder or significant negative mood [1]. More recently, a more holistic and multidimensional approach has been advocated by some authors. Larsen and Hummel [2] argued that adjustment should include not only the way patients manage the medical and physical challenges of their disease, but also other areas of functioning including cognitive, emotional, behavioral, and psychological domains. Consistent with this, Stanton, Revenson, and Tenner [3] emphasized the importance of evaluating adjustment across multiple domains and of assessing both positive and negative indicators (e.g., quality of life; depression). Despite these recommendations, the most commonly studied markers of adjustment are symptoms of anxiety and depression, and psychological distress. These negative outcomes are viewed as prevalent difficulties in cancer patients and their screening is advocated by different entities such as The National Cancer Institute or The International Psycho-Oncology Society.

Stanton et al. [3] conceptualized adjustment as a dynamic process in which adaptive tasks change over time depending on the course of the disease and one that is influenced by contextual factors. They emphasize the heterogeneous nature of adjustment as indicated by the marked variability in the way people respond to disease. It seems that psychological adjustment to BC may vary according to the stage of the disease. Studies exploring psychological adjustment have found different results if they were conducted with women with a recent diagnosis/during treatments or with women 
that had already finished treatments. At diagnosis/during treatment, studies show that women tend to present elevated levels of anxiety, depressive symptoms, and general psychological distress, and report lower levels of quality of life [4-6].

Challenges, however, extend well beyond short-term coping with diagnosis and treatments. BC survivors have to grapple with potential long-term effects of the disease and its treatment. Given the increased number of BC survivors, research has begun to focus on understanding longer-term psychological adjustment in order to provide more effective care to cancer patients from diagnosis through survivorship. The results from longitudinal studies, however, are mixed. Some studies evidence that BC survivors show strong adjustment following the conclusion of treatment, presenting normative levels of anxiety, depression, psychological distress, and quality of life $[5,7,8]$. Other studies indicate that some impairments endure over longer periods. Physical (e.g., pain), psychological (e.g., psychological distress), and social (e.g., role functioning) difficulties are reported by BC survivors even many years after diagnosis [9-12].

In fact, there is marked variability in trajectories of adjustment from diagnosis into sustained survivorship [13]. Both cross-sectional and longitudinal studies indicate that individual differences in adjustment are associated with a wide range of factors, including sociodemographic (e.g., age, education), disease-related (e.g., treatment type), and psychosocial factors (e.g., social support, optimism) [7,12,14-19].

A systematic review of longitudinal studies exploring the factors associated with psychological adjustment to $\mathrm{BC}$ is needed to organize current knowledge about these factors in a rigorous and replicable way. The identification of factors that facilitate or hinder psychological adjustment can help providers identify those women who are at greater risk for adjustment difficulties, can inform psychosocial interventions designed 
to address women's needs when adapting to $\mathrm{BC}$, and can guide the tailoring of interventions to meet individual patients' particular needs.

This systematic review aims to analyze longitudinal studies that examine factors that predict psychological adjustment of women with BC. Psychological adjustment in in this review was defined as the absence of indicators of distress, including psychological symptoms, and the presence of indicators consistent with perceptions of a positive quality of life. This systematic review focuses on factors assessed close to the time of diagnosis (including pre-diagnosis) that might predict later adjustment to BC. Both positive and negative aspects of psychological adjustment are considered. A primary focus is on potentially malleable predictors, since they could be targeted for change in future interventions. Non-modifiable demographic and clinical factors (e.g., age) were also considered since they can inform clinicians about women who most need and can benefit from psychological interventions.

\section{Method}

The PRISMA guidelines for reporting of systematic reviews and meta-analyses were followed [20].

\section{Eligibility criteria}

Longitudinal studies exploring factors associated with the psychological adjustment of women with BC were included. Inclusion criteria: (1) quantitative and longitudinal studies written in English and published in a peer-reviewed journal; (2) the independent variables studied must include demographic, disease-related, or psychosocial variables and should be measured before the time of diagnosis, close after the time of diagnosis, or during treatments; and (3) the outcome variables needed to be indicators of psychological adjustment. Exclusion criteria: (1) studies that included 
other types of cancer; (2) literature reviews, books, unpublished studies including doctoral theses, commentaries, abstracts of conferences, case-reports, and qualitative studies; (3) studies without predictors (e.g., studies focusing only on trajectories of psychological adjustment across time); (4) experimental studies (e.g., women evaluated after randomized participation in a psychosocial intervention); (5) cross-sectional studies; and (6) studies with fewer than 50 participants, which do not have sufficient power to reliably detect significant associations [21]. No constraints were made regarding the number of waves of assessment and the range of follow-up assessment of the studies.

\section{Search strategy}

The following databases were searched for studies published between January 2000 and December 2015: Academic Search Complete, CINAHL plus, ERIC, MedicLatina, MEDLINE, PsycARTICLES, PsycCRITIQUES, Psychology and Behavioral Sciences Collection, and PsycINFO. This search was supplemented by additional hand-searching in Google and checking reference lists. The search terms covered three groups of keywords: (1) breast cancer OR mastectomy OR breast neoplasm defined the population AND (2) psychological distress OR psychological adjustment OR psychological adaptation OR depression OR anxiety OR emotional distress OR emotional adjustment OR emotional adaptation OR distress OR stress OR quality of life defined the health outcomes of interest (3) AND longitudinal study OR prospective study OR follow-up study defined the study design.

The first author screened titles and abstracts of potential articles to be included by applying the stated inclusion and exclusion criteria. An independent researcher 
reviewed a random sampling of $30 \%$ of the studies originally identified. No discrepancies in inclusion decisions between reviewers were found.

\section{Results}

\section{Description of included studies}

The search yielded an initial pool of 1780 articles. A total of 42 studies were included. Two articles [22,23] had overlapping samples from the same study, so the final sample was reduced to 41 . The study selection procedure is outlined in supplemental data Figure 1.

Studies were most commonly conducted in the USA $(n=10)$ and the Netherlands $(n=8)$ but there was a wide variety of other countries (Australia, Canada, France, Greece, Hong Kong, Iran, Japan, Norway, Portugal, Spain, South Korea, Sweden, Taiwan, and United Kingdom). Evidence was gathered from 9361 participants (range = 50-763 participants) with a mean age of 53.72 years $(S D=3.81)$. The number of assessment waves in these longitudinal studies ranged from two to six (Mean=3; $S D=1.15)$ and follow-up varied between two months post-diagnosis to ten years postdiagnosis (Mean=21.1 months; $S D=28.51)$. It is important to note that some studies included a short-term follow-up assessment that likely included participants that were still in treatment [24]. Baseline assessment was done after diagnosis/surgery in the majority of the studies ( $n=29$ studies; 71\%). In twelve studies, baseline assessment was done before diagnosis (29\%). Attrition rates in the 34 studies ranged from $0 \%$ to $63 \%$ (Mean=22.88; $S D=15.31)$. The majority of studies $(n=38)$ used regression-based approaches $^{1}$. Only 20 studies $(49 \%)$ controlled baseline levels of main outcomes. This is

\footnotetext{
${ }^{1}$ The majority of studies failed to provide sufficient details about bivariate versus multivariate analyses and controlled variables. We recognize it is difficult to compare results where different variables are
} 
an important aspect because controlling for baseline levels shifts the focus of studies effectively to change in adjustment from the original baseline rather than just focusing on absolute levels of adjustment at follow-up.

The majority of studies focused on only one indicator of psychological adjustment $(n=30)$. Five different categories of outcomes were used to assess psychological adjustment to $\mathrm{BC}^{2}$. These five different categories were assessed using 20 different self-report instruments (see supplemental data-Table 1). Quality of Life, assessed in 18 studies, was the most common psychological outcome and was measured most often with the World Health Organization Quality of Life $(n=7)$. The second most commonly measured outcome was psychological distress $(n=15)$. A wide variety of instruments were used to assess psychological distress. The most common ( $n=3$ each) were the General Health Questionnaire (GHQ), the Hospital Anxiety and Depression Scale (HADS), and the Profile of Mood State (POMS). Depressive symptoms were the third most commonly measured outcome $(n=13)$ with the Center for Epidemiologic Studies Depression Scale being the most common instrument used ( $n=6)$. Anxiety symptoms were evaluated by six studies, mainly with the HADS. The least frequently measured psychological outcome was mood, which was assessed by two studies using the POMS or the PANAS). See supplemental data-Table 2 for a detailed description of studies.

\section{Factors associated with psychological adjustment}

controlled. We made an effort to take this information (when reported) into consideration in the results section. We thank reviewer for highlighting this issue.

${ }^{2}$ In our view, it is helpful to organize the 19 different instruments into five conceptual domains. We think these 5 conceptual domains represent the main areas of psychological adjustment that have been studied. We do not think it would be useful to collapse them further because this would result in a loss of information. 
A wide variety of factors were explored as potential predictors. The predictors were organized into three conceptually-meaningful groups: sociodemographic, diseaserelated or physical, and psychosocial factors. This organization reflects the way how majority of studies presented their results. The associations found between potential predictors and indicators of psychological adjustment are summarized in supplemental data-Table 3.

\section{Sociodemographic factors}

Six different sociodemographic variables were tested as potential predictors: age (17), education level (12), marital status (7), employment status (6), income (3), and children living at home (3).

With regard to age, the results were mixed. Of the 17 studies, only ten found significant associations between age and psychological adjustment [22,25-32]. Older age predicted better quality of life [22,29,33,34], less depression [17,35], and less psychological distress [36,37]. Avis et al. [17] found that older women (> 65 years) reported fewer depressive symptoms, but when other variables were entered as covariates (e.g., chemotherapy, coping strategies) age differences disappeared. In three studies, older age predicted poorer quality of life in terms of physical functioning, role functioning, and vitality [16,29,38].

Regarding education level, three studies found that higher education level predicted better quality of life and fewer depressive symptoms $[22,39,40]$. Nine studies found no association [17,25,28,29,31-35]. Concerning marital status, the results of two studies showed that being partnered predicted less psychological distress [39], fewer depressive symptoms [31,39], and better quality of life [31]. However, five studies did not find any association $[17,25,28,32,33]$. 
Two studies indicated that lower income predicted poorer quality of life [33] and more depressive symptoms [27]. One study found no association [41]. Employment status was a significant predictor of quality of life in only one [29] of six studies $[25,28,30,32,39]$. Presence of children in the home $[17,28,32]$ was not a predictor of psychological adjustment.

\section{Disease-related and physical factors}

Twenty seven different disease-related or physical variables were explored as potential predictors: chemotherapy (10), type of surgery (8), staging of BC (6), time since diagnosis (5), fatigue (5), radiation (5), sleep difficulties (4), hormone therapy (4), pain (3), combined treatments (3), physical functioning (3), diagnosis (benign vs malign) (2), overall physical symptom distress (2), comorbidities (2), number of affected lymph nodes (2), role functioning (1), time since treatment's end (1), recurrence (1), lingering side effects (1), dependence on medication (1), health complaints (1), smoking (1), satisfaction with physical ability to work (1), limited shoulder movement (1), numbness (1), and menopause status (1).

Regarding associations with chemotherapy regimens, three studies found that women who had undergone chemotherapy reported worse quality of life than those who did not $[16,30,38]$. In one study, completing chemotherapy with doxorubicin predicted a decline in depressive symptoms as compared to chemotherapy without doxorubicin or no chemotherapy [17]. Two studies did not find any association between undergoing chemotherapy and psychosocial adjustment [32,39]. In one study, women who had received systematic adjuvant therapy (i.e., chemotherapy, tamoxifen, or both) reported worse quality of life than those who did not [33]. Five studies did not find any association between radiation and psychological adjustment [17,27,29,32,35]. 
Regarding type of surgery, studies focused on psychological adjustment following breast conserving strategies (e.g., lumpectomy) as compared to full mastectomies or comparisons between women who had surgery and those that did not. Results are inconsistent. In one study breast conserving surgery compared to mastectomy predicted better quality of life [16] while in two studies it was associated with poorer quality of life $[22,30]$. One study found that lumpectomy compared to no lumpectomy predicted poorer quality of life [38]. Four studies found no association between type of surgery (lumpectomy vs mastectomy) and psychological adjustment $[17,29,33,35]$.

Five studies explored the relationship between time since diagnosis and psychological adjustment. In one study, time since diagnosis predicted quality of life, with women being on average 4 years post-diagnosis presenting better quality of life [38]. In four studies, however, no associations were found between time since diagnosis and psychological adjustment [17,33,34,39]. Fatigue predicted more depressive symptoms [28,32], more anxiety [31], and worse quality of life [25] while no association between fatigue and psychological adjustment was found in only one study [41]. Hormone therapy did not predict psychological adjustment in any of the four studies that examined this question $[29,30,32,33]$.

Three studies found that advanced cancer stage predicted poorer quality of life $[22,25,29]$ but two studies found no associations $[17,31]$. Two studies examined the association between the number of lymph nodes affected and psychological adjustment. In one study it was examined links between psychological adjustment and lingering side effects associated with lymph node removal. More lymph nodes affected and more side effects associated with lymph node dissection predicted poorer quality of life [38]. The other study did not find an association between number of affected lymph nodes and 
psychological adjustment [35]. Only one study explored the predictive role of time since treatment end on psychological adjustment. The authors found that emotional distress decreased with time since treatment [39]. Finally, the subjective perception that quality of life depends on the use of medications predicted better quality of life [41].

Sleep difficulties predicted more psychological distress [42] and poorer quality of life [28], but three studies found no significant associations [25,26,41]. Reports of more pain predicted more depressive [17,31] and anxiety symptoms [31]. However, one study found no significant associations between pain and these variables [41]. Two studies found that overall distress over physical symptoms predicted more depressive symptoms [43] and worse quality of life [25], but one study found no association with anxiety [43]. Reports of better physical functioning or less physical impairment predicted less psychological distress [36] and better quality of life [33]. Health complaints predicted more psychological distress [42] and limited shoulder movement predicted worse quality of life [25]. Smoking, satisfaction with physical ability to work, and numbness did not predict psychological adjustment $[25,27,41]$. The ability to perform work and other roles without limitations predicted better quality of life [38] and fewer depressive symptoms [27]. One study explored the association between menopause status and psychological adjustment. The authors found that menopausal women reported more depressive symptoms than non-menopausal women [27].

\section{Psychosocial factors}

Psychosocial variables were grouped into six categories to facilitate presentation and understanding: psychological functioning or state variables, personality traits, coping strategies, social support variables, cognitive or perceptual factors, and body image variables. 


\section{Psychological functioning/state}

Three different psychological functioning or state variables were explored: anxiety (3), depression (3), and psychological well-being (2).

Symptoms of anxiety were predictive of worse later quality of life $[25,34]$ and depression [44]. Symptoms of depression were predictive of worse quality of life $[30,34]$ and more anxiety [44]. On the contrary, psychological well-being at diagnosis predicted better quality of life [33] and fewer depressive symptoms at follow-up [26].

Seventeen studies $(41 \%)$ provided evidence that initial levels of the main psychological outcome influenced the outcome at follow-up. It is important to note that the majority of studies did not control for baseline levels of the main outcomes (24 studies; 59\%). Initial levels of psychological distress, anxiety, depression, and worse quality of life at baseline predicted worse outcome on these measures at follow-up $[16,22,24,28,34-37,39,42-, 49]$. In two studies, initial levels of the main outcomes were controlled as confounders but their predictive power was not reported [50,51]. In one study, the initial levels of the main psychological outcome (i.e., depressive symptoms) did not predict the outcome at follow-up [32].

\section{Personality traits}

Five personality traits were tested as potential predictors: optimism (6), traitanxiety (3), neuroticism (2), pessimism (1), hope (1), agreeableness (1), and conscientiousness (1).

Trait-anxiety predicted more depressive symptoms [28,32] and poorer quality of life [28,52]). In two studies, trait-anxiety did not predict quality of life [34,40]. Optimism predicted better quality of life [16], more positive affect [52], and lower 
levels of anxiety $[43,53,54]$, depression $[39,43,53,54]$, and psychological distress [39]. Neuroticism predicted more psychological distress [47] and worse quality of life [40]. Pessimism [54], hope [53], agreeableness and conscientiousness [40] were not significant predictors of psychosocial adjustment.

\section{Coping strategies}

Coping strategies were examined as potential predictors in eleven studies (27\%). Coping strategies generally considered as less adaptive, such as avoidance, repression, passive coping, acceptance/resignation, and cancer-related rumination or anxious preoccupation predicted more psychological distress and depressive symptoms [17,24,34,37,43,45,55]. Strategies, such as positive reappraisal, problem-solving, religious coping, and dyadic coping that are generally considered more adaptive were associated with better quality of life, less mood disturbance, less psychological distress, and fewer depressive symptoms $[17,22,35,45,56]$. One study found that perceptions of a lack of decisional control predicted more psychological distress [45] but only when coping strategies and baseline levels of psychological distress were not entered in the analysis. One study did not find any association between rumination and psychological distress [57].

\section{Social support variables}

Two different sets of social factors were explored as potential predictors. One set (9) focused on overall social support and the other (3) on close relationship support. Perception of greater overall social support predicted greater quality of life $[8,29,33,34,38]$ and fewer depressive symptoms [17,27] but did not predict psychological distress [55]. A sense of isolation predicted higher levels of anxiety in one study [49]. Support from physician predicted better quality of life [29]. Supportive 
care from partners predicted less psychological distress [50]. A communication style characterized by mutually constructive exchanges with a partner predicted less psychological distress. In contrast, communication styles characterized by mutual avoidance or mismatches of engagement predicted more psychological distress [50]. Attachment style did not predict psychological adjustment [26].

\section{Cognitive and perceptual factors}

Eleven different variables related to cognitive and perceptual factors were explored as potential predictors, namely perceived control (3), self-efficacy (3), intrusion (2), sense of coherence (1), helplessness/hopelessness (1), psychological needs (1), expectancy outcome incongruence (1), confidence of remaining cancer free (1), illness perception identity (1), goal adjustment (1), and passive decisional preference (1).

Appraisals and illness perceptions of this type are widely viewed as important determinants of reactions to stress [58]. Perceived control predicted less psychological distress [59] and lower anxiety [46,49]. One study did not find any association between perceived control and psychological distress [46]. A sense of self-efficacy predicted better quality of life [25] and less psychological distress [51]. Intrusion of illness-related thoughts or worries predicted more depressive symptoms [17] but did not predict psychological distress [24]. A view of life as comprehensible, manageable and meaningful (i.e., coherence) predicted quality of life [29]. Helplessness/hopelessness predicted more psychological distress [24]. Reports of psychological needs not being met predicted more anxiety and depressive symptoms [43]. Incongruence between the expected and the perceived impact of surgery on appearance and social relationships predicted more psychological distress [51]. Confidence about remaining cancer free 
predicted better quality of life and more psychological distress [39]. Illness perception identity, which was measured by the number of symptoms that the patient perceived to be part of the illness, predicted greater psychological distress [47]. In one study, goal engagement predicted lower levels of anxiety [52], but did not predict depression nor quality of life [53]. A passive decisional preference did not predict quality of life [34].

\section{Body image variables}

Five different variables related to body image were explored as potential predictors: perceived body image (2), appearance satisfaction (2), self-consciousness (2), self-evaluation salience (1), and efforts to be or feel attractive (1).

In two studies, better body image and more satisfaction with appearance predicted better quality of life [25,30]. One study found that neither body image nor appearance satisfaction predicted anxiety, depression, or quality of life [48]. Selfconsciousness around appearance did not predict anxiety, depression, or quality of life [48]. However, self-evaluation salience (i.e., beliefs about how appearance influences one's self-worth) predicted more depressive symptoms [48]. Individuals' efforts to be or feel attractive predicted fewer depressive symptoms [48]. ${ }^{3}$

\section{Moderators and mediators}

A small number of studies (6) have used mediational analyses to explore mechanisms that might explain linkages found. Cousson-gélie [60] found evidence for the mediating role of self-accusation (i.e., coping marked by self-blame) and distress in

\footnotetext{
${ }^{3}$ An additional analysis of the results was performed taking into account only studies with larger samples ( $N>150$ participants, 28 studies). The exclusion of the more weakly powered studies (the ones with n's under 150) does not result in major differences in the results obtained. The differences were the following: (1) some predictors that were analyzed only by the excluded studies, such as repression or positive reappraisal, are no longer relevant; (2) studies assessing the association between stage of disease and psychological adjustment were no longer included. These studies with relatively smaller samples did find significant associations, suggesting that lack of power was not a major issue.
} 
the association between trait anxiety at baseline and later quality of life. Rohani et al. (23) found that sense of coherence mediated the relationship between earlier and later quality of life. Helplessness/hopelessness mediated the relationship between emotional suppression and psychological distress [24]. Engagement in social life and threat appraisal (but not active patient participation or coping self-efficacy) mediated the link between perceived control and anxiety in another study [46]. Posttraumatic growth mediated the connections of perceived social support to quality of life and to depressive symptoms [61]. No evidence was found in support of the mediating role of avoidance of thinking about cancer and related-thoughts in explaining the relationship between intrusion and psychological distress [57].

Even rarer is the investigation of moderators that might shape individual differences in links between identified predictors and markers of adjustment. One study indicated that physical impairment did not moderate the link between communication style and psychological distress [50]. In another study, the authors found that an active decisional preference predicted better quality of life but only for those women who presented lower levels of repression of emotions [34].

\section{Discussion}

The goal of this systematic review was to synthesize existing research from longitudinal studies that assess which sociodemographic, disease-related, and psychosocial factors near diagnosis predicted later psychological adjustment to BC. To the best of our knowledge there are no previous systematic reviews focusing on this topic. It is important to note, however, that results presented here should be interpreted with caution. This is because studies varied greatly in their sample size, and the 
majority of the results did not present the effect size (ES) for the results obtained. For this reason, a consistency/inconsistency approach was adopted.

Overall results indicate that the majority of sociodemographic factors and disease-related or physical factors examined have not been consistently associated with psychological adjustment to BC. For sociodemographic factors, income is the only factor that is consistently related to psychosocial adjustment, with lower income being related to more depressive symptoms and worse quality of life ${ }^{4}$. For disease-related or physical variables only fatigue, cancer stage, and physical functioning seem to consistently predict psychological adjustment. Fatigue was associated with more depression and anxiety and worse quality of life. An advanced stage was associated with worse quality of life. Better physical functioning was associated with better quality of life, and less depressive symptomatology and psychological distress. Many factors warrant further investigation, especially psychosocial factors that were examined by only a few studies, such as hope, repression, and attachment style.

The sociodemographic results suggest that it is important to ask patients about financial resources in order to identify those who are at higher risk for developing psychological distress. It may be useful to provide women likely to experience financial strain access to both additional psychological support and to resources that may help them reduce their financial burden. Simple and relatively low-cost initiatives such as providing transportation assistance may also be helpful for these vulnerable populations.

In terms of disease-related or physical factors, the results point to the importance of assessing fatigue-related challenges and the potential benefits of offering

\footnotetext{
${ }^{4}$ Quality of life measures that include both a physical and psychological component may obscure differences in predictors of adjustment in these two spheres. More research is needed to identify whether in fact this is the case. We thank an anonymous reviewer for highlighting this possibility.
} 
psychosocial treatments that target fatigue (e.g., fatigue education, coping strategies). Since advanced stage is associated with worse psychological adjustment, these results point to the potential benefits of early identification of BC. Women with metastatic BC are especially vulnerable and should have access to psychological support in order to promote their psychological adjustment. As whole, these results suggest the importance of integrated, multidisciplinary care for cancer patients (e.g., social workers to address financial strains, psychologists helping to screen for and address distress).

Contradictory results for sociodemographic and disease-related or physical factors emerged for age and type of surgery. These contradictory results have been documented in previous reviews $[62,63]$. Our results suggest that the psychological impact of $\mathrm{BC}$ is stronger for younger women, especially when considering signs of depression and psychological distress. Research suggests that younger women are less likely to anticipate the onset of cancer, are usually submitted to more aggressive neoadjuvant treatments, and have to deal with age-specific challenges (e.g., treatmentinduced infertility, fears associated with the impossibility of seeing their children growing up) [62]. In some studies, there are indications that older women may be more susceptible to perceived declines in physical and cognitive functioning related to BC and its treatment that may be related to overall physical limitations that accompany aging.

Regarding type of surgery, inconsistencies found in the included studies seem to be consistent with previous reviews [63]. The belief that the less invasive approach of breast conserving surgery as compared to more radical surgeries would be linked to better psychological adjustment is not consistently supported. Preserving the breast can lead to increased anxiety about cancer recurrence or can limit social support associated with a devaluation of the seriousness of the situation [63]. It seems that more important 
than the type of surgery is the impact of the diagnosis itself and the adjuvant treatments undertaken. Although these demographic and disease-related predictors are not easily modified, it is important to recognize their role in psychological adjustment in order to identify those women who are at greater risk for experiencing psychological difficulties and that should be referred to psychological intervention.

With regard to psychosocial factors, the majority of predictors were analyzed only in one study or a few studies, which makes it hard to find consistencies. The following factors were predictive of better psychological adjustment in more than one study: optimism, initial psychological well-being, perceived social support, perceived control, and self-efficacy. These variables have been identified in the literature as protective factors for psychological adjustment and for health outcomes, in general. For example, optimism and the perceived quantity and the quality of social support have been reliably linked to a variety of mental and health outcomes [e.g., 64,65]. Women with a more optimistic view may more directly confront and face disease-related challenges, engage more actively in treatment, enact more positive health behaviors, and cope with stress better, all of which can contribute to their psychological well-being [66]. Perceptions of emotional support and practical aid are likely to help reduce stress burdens and reactivity in a number of ways that have been well-documented [65]. For example, women with $\mathrm{BC}$ who feel supported are likely to feel they are not alone in dealing with their challenges and that important others can help them cope with not only with discrete disease-related demands but also with larger psychological burdens and with larger life questions that arise when dealing with a life-threatening condition.

Perceived control and self-efficacy have been widely associated with improvements in health behaviors, psychological well-being, and health outcomes [e.g., $67,68]$. Individuals who believe in their ability to deal with obstacles and challenges are 
more likely to initiate a set of actions to deal with them and be more persistent in facing difficulties [66,69]. More adaptive coping strategies (such as positive reappraisal), and body image and appearance satisfaction emerged as protective factors but they were only examined in one study. It is important for further research to study these factors in order to determine if they are robust predictors of psychological adjustment for women with BC.

In contrast to these psychosocial factors that were associated with positive adaption, neuroticism, trait-anxiety, and less adaptive coping strategies (such as anxious preoccupation, avoidance, or rumination) emerged as consistent risk factors for psychological distress and poorer quality of life. The personality traits of neuroticism and trait-anxiety are linked more widely with a number of mental and physical disorders that have bearing on the quality and longevity of people's life [70,71]. Coping strategies marked by higher levels of avoidance and/or rumination have also been associated with a number of negative psychological and physical outcomes and are a consistent risk factor for the development of psychological disorders [72-74]. Personality traits shape the way individuals appraise and deal with an adverse situation. Repetitive thinking about negative events, bodily threats or affect and attempts to avoid or deny negative emotions or situations may lead to social withdrawal, less engagement in health behaviors, and more psychological distress contributing to difficulties adapting when facing BC. Unsupportive care from partners, negative communication style, helplessness/hopelessness, and lower appearance investment emerged as risk factors but were tested only by one study. Further research on the associations between these factors and psychological adjustment to BC is warranted.

In terms of clinical implications, the results showed that initials levels of anxiety symptoms, depression symptoms, general psychological distress, and quality of life 
predict subsequent psychological adjustment. These findings suggest that it would be helpful to screen BC patients for their level of psychological adjustment at diagnosis and during treatments. The Distress Thermometer (National Comprehensive Cancer Network, 2013) or the Emotion Thermometers [75] are simple, rapid, and valid tools for detecting and monitoring emotional distress in cancer patients that can be easily used by clinicians to screen for psychological distress. Women who show evidence of elevated risk for poor psychological adjustment can be given a list of resources for additional support. The results of the review also highlight the predictive importance of personality traits (e.g., optimism, neuroticism), coping strategies, and relational factors (e.g., interaction with partners in terms of caregiving and communication style). Personality traits by themselves are difficult to change but coping strategies can be taught to address particular challenges common to individuals with risky traits. Similarly, interventions have been proposed and are available to boost relational support for $\mathrm{BC}$ patients $[76,77]$.

In sum, the results from psychosocial predictors emphasize the need for incorporating psychological components into health care services for cancer patients. Psychosocial resources and services are especially important to cancer patients showing signs of risk at the outset of diagnosis and treatment.

\section{Conclusions and recommendations for future research}

This review identifies consistent predictors of psychological adjustment to BC and some important directions for future research. The most consistent predictors identified were income, fatigue, advanced stage, physical functioning, optimism, traitanxiety, social support, coping strategies, and initial levels of psychological functioning. Other variables, namely cognitive and body image factors were also found to be 
predictors of later psychological adjustment but were assessed in a limited number of studies. Age and type of surgery were inconsistently predictive of psychological adjustment.

The findings from this review suggest that it might be useful to identify women at greatest risk for psychological distress at the time of diagnosis. Supportive resources and interventions could then be directed to these at-risk patients. The failure of studies identified in this review to consistently report ES (only eleven studies reported ES) is problematic. Without this specific information, it is difficult to judge the overall predictive power of factors across studies. Small to medium effects were found for those studies that did report information about ES. It is important to note that this systematic review that focused on longitudinal studies only found 41 studies. Although longitudinal research is costly and difficult to conduct for many reasons (e.g., participants' attrition, human/financial resources) it is essential to better understand the long-term process of adjustment to $\mathrm{BC}$.

The included studies vary widely in the variables they focus on and in the methods used. These differences may explain some of the inconsistencies found. Variation in the predictive value of certain variables may also reflect the work of unknown psychosocial moderators (e.g., marital satisfaction) that might facilitate or impair the adjustment of certain kinds of women.

Some differences between studies may reflect additional methodological issues. Studies varied in the number of waves of assessment used and the range of follow-up assessment ranged greatly (from months to years). Some studies included follow-up assessments with women who were still in treatment. A close examination of the results, however, did not indicate large variation in important predictors between short- and 
long-term outcomes but further research on this topic would be useful. Sample sizes varied from 50 to 763 and the number of predictors entered and controlled in analyses also varied widely. Some studies reviewed failed to control for baseline levels of the outcome. The absence of these controls makes it difficult to separate out long-standing differences in adjustment from those specific to BC. Finally, the way psychological adjustment was conceptualized and measured differed in important ways across studies. Five different domains of outcomes were evaluated and 19 different instruments were used.

Almost all of the studies focused on adjustment as a primarily individual process and construct. Future research would benefit from integrating relational views that more explicitly incorporate the experiences of important others and view psychological adjustment in its broader social context. The process of adjustment involves continuous exchanges between the patient and her social environment that are likely to have farreaching influences for the patient's functioning. Studies should include relational variables such as, marital/relationship quality, patterns of attachment to parents and romantic partners. Studies are needed that track the reciprocal relationship between functioning following $\mathrm{BC}$ diagnosis and the quality of a patient's relationship with a partner. Studies often reduce relational effects down to social support measures that do not adequately capture the complexity and importance of a patient's primary relationship. Methodological approaches that capture important dynamics in relationships, such as dyadic analyses and multi-informant reporting [78] can facilitate this work.

A surprising result was the relatively rarity of studies examining emotional regulation variables. Although some studies examined dimensions related to emotion regulation (e.g., coping, rumination), there are constructs central to emotion regulation 
that have not been studied sufficiently (e.g., suppression, positive reappraisal). Since emotion regulation and expression play an important role in psychological adjustment in the context of $\mathrm{BC}[79,80]$, we recommend the inclusion of such variables in future studies in order to examine if and how they influence long-term psychological adjustment to $\mathrm{BC}$. 


\section{REFERENCES}

1. Stanton AL, Collins CA, Sworowski LA. Adjustment to chronic illness: Theory and research. In Handbook of health Psychology, Baum A, Revenson TA, Singer JE (eds). Erlbaum, New York; 2001; 387-403.

2. Larsen P, Hummel F. Adaptation to chronic illness. In Chronic illness impact and interventions, Larsen P, Lubkin IM, (eds) (8th de). Jones and Bartlett, Boston; 2013.

3. Stanton AL, Revenson TA, Tennen H. Health psychology: Psychological adjustment to chronic disease. Annual Review of Psychology 2007;58:565-592. DOI: 10.1146/annurev.psych.58.110405.085615

4. Burgess C, Cornelius V, Love S, Graham J, Richards M, Ramirez A. Depression and anxiety in women with early breast cancer: Five year observational cohort study. BMJ 2005;330:702-706. DOI: 10.1136/bmj.38343.670868.D3

5. Moreira H, Silva S, Canavarro MC. Qualidade de vida e ajustamento psicossocial da mulher com cancro da mama: Do diagnóstico à sobrevivência [Quality of life and psychosocial adjustment in women with breast cance: From diganosis to survivorship]. Psicologia, Saúde \& Doenças 2008;9:165-184.

6. Stafford L, Judd F, Gibson P, Komiti A, Mann GB, Quinn M. Screening for depression and anxiety in women with breast and gynaecologic cancer: course and prevalence of morbidity over 12 months. Psycho-Oncology 2013;22:2071-2078. DOI: $10.1002 /$ pon.3253

7. Costanzo ES, Lutgendorf SK, Mattes ML, Trehan S, Robinson CB, Tewfik F, Roman SL. Adjusting to life after treatment: Distress and quality of life following treatment for breast cancer. British Journal of Cancer 2007;97:1625-1631. DOI: 10.1038/sj.bjc.6604091

8. Leung J, Pachana NA, McLaughlin D. Social support and health-related quality of life in women with breast cancer: A longitudinal study. Psycho-Oncology 2014;23:1014-1020. DOI: 10.1002/pon.3523

9. Aguado Loi CX, Baldwin JA, McDermott RJ, McMillan S, Martinez Tyson D, Vanderweerd C. Risk factors associated with increased depressive symptoms 
among Latinas diagnosed with breast cancer within 5 years of survivorship. Psycho-Oncology 2013;22:2779-2788. DOI: 10.1002/pon.3357

10. Gao J, Dizon DS. Preparing for survivorship: Quality of life in breast cancer survivors. The Journal of Sexual Medicine 2013;10:16-20. DOI: $10.1111 /$ jsm. 12029

11. Holzner B, Kemmler G, Kopp M, Moschen R, Schweigkofler H, ... SpernerUnterweger B. Quality of life in breast cancer patients - not enough attention for long-term survivors? Psychosomatics 2001;42:117-123. DOI: 10.1176/appi-psy-422-117

12. Koch L, Jansen L, Herrmann A, Stegmaier C, Holleczek B, Singer S, Brenner H, Arndt V. Quality of life in long-term breast cancer survivors - a 10-year longitudinal population-based study. Acta Oncologica 2013;52:1119-1128. DOI: 10.3109/0284186X.2013.774461

13. Stanton AL, Bower JE. Psychological adjustment in breast cancer survivors. $\underline{\text { In}}$ Improving outcomes for breast cancer survivors: Perspectives on research challenges and opportunities Ganz PA (ed). Springer International Publishing; 2015; 231-242. DOI: 10.1007/978-3-319-16366-6

14. Arndt V, Stegmaier C, Ziegler H, Brenner H. Quality of life over 5 years in women with breast cancer after breast-conserving therapy versus mastectomy: A population-based study. Journal of Cancer Research and Clinical Oncology 2008;134:1311-1318. DOI: 10.1007/s00432-008-0418-y

15. Bloom JR, Petersen DM, Kang SH. Multi-dimensional quality of life among longterm (5+ years) adult cancer survivors. Psycho-Oncology 2007:16:691-706. DOI: 10.1002/pon. 1208

16. Schou I, Ekeberg Ø, Sandvik L, Hjermstad MJ, Ruland CM. Multiple predictors of health-related quality of life in early stage breast cancer. Data from a year followup study compared with the general population. Quality of Life Research 2005;14:1813-1823. DOI: 10.1007/s11136-005-4344-z

17. Avis NE, Levine B, Naughton MJ, Case LD, Naftalis E. Age-related longitudinal changes in depressive symptoms following breast cancer diagnosis and treatment. 
Breast Cancer Research Treatment 2013;139:199-206. DOI: 10.1007/s10549-0132513-2

18. Kornblith AB, Herndon JE, Zuckerman E, Viscoli CM, Horwitz RI, ... Holland J. Social support as a buffer to the psychological impact of stressful life events in women with breast cancer. Cancer 2001;91:443-454. DOI: 10.1002/10970142.

19. Schnoll RA, Knowles JC, Harlow L. Correlates of adjustment among cancer survivors. Journal of Psychosocial Oncology 2002;20:37-60. DOI: 10.1300/J077v20n01_03

20. Moher D, Liberati A, Tetzlaff J, Altma DG, The PRISMA Group. Preferred reporting items for systematic reviews and meta-analyses: The PRISMA Statement. Annals of Internal Medicine 2009;151:65-94. DOI: 10.7326/0003-4819-151-4200908180-00136

21. VanVoorhis CW, Morgan BL. Understanding power and rules of thumb for determining sample sizes. Tutorials in Quantitative Methods for Psychology 2007;3:43-50.

22. Rohani C, Abedi H, Omranipour R, Langius-Eklof A. Health-related quality of life and the predictive role of sense of coherence, spirituality and religious coping in a sample of Iranian women with breast cancer: a prospective study with comparative design. Health and Quality of Life Outcomes 2015;13:1-14. doi: 10.1186/s12955015-0229-1

23. Rohani C, Abedi H, Sundberg K, Langius-Eklof A. Sense of coherence as a mediator of health-related quality of life dimensions in patients with breast cancer: a longitudinal study with prospective design. Health and Quality of Life Outcomes 2015;13:1-9. doi 10.1186/s12955-015-0392-4

24. Andreu Y, Galdón MJ, Durá E, Martínez P, Pérez S, Murgui S. A longitudinal study of psychosocial distress in breast cancer: prevalence and risk factors. Psychology \& Health 2012;27:72-87. doi:10.1080/08870446.2010.542814

25. Cheng SY, Lai YH, Chen SC, Shun SC, Liao YM, Tu SH, ... Chen CM. Changes in quality of life among newly diagnosed breast cancer patients in Taiwan. Journal of Clinical Nursing 2012;21:70-79. doi: 10.1111/j.1365-2702.2011.03735.x 
26. Hsiao FH, Chang KJ, Kuo WH, Huang CS, Liu YF, Lai YM ... Chan CL. A longitudinal study of cortisol responses, sleep problems, and psychological wellbeing as the predictors of changes in depressive symptoms among breast cancer survivors. Psychoneuroendocrinology 2013;38:356-366. DOI: 10.1016/j.psyneuen.2012.06.010

27. Lee MK, Park S, Lee ES, Ro J, Kang HS, Shin KH, ... Yun YH. Social support and depressive mood 1 year after diagnosis of breast cancer compared with the general female population: a prospective cohort study. Supportive Care Cancer 2011;19:1379-1392. DOI: 10.1007/s00520-010-0960-4

28. Lockefeer JPM, De Vries J. What is the relationship between trait anxiety and depressive symptoms, fatigue, and low sleep quality following breast cancer surgery? Psycho-Oncology 2013;22:1127-1133. DOI: 10.1002/pon.3115

29. Maly RC, Liu Y, Liang LJ, Ganz PA. Quality of life over 5 years after a breast cancer diagnosis among low-income women: effects of race/ethnicity and patientphysician communication. Cancer 2015; 15:916-926. doi: 10.1002/cncr.29150

30. Taira N, Shimozuma K, Shiroiwa T, Ohsumi S, Kuroi K, Saji S, ... Katsumata N. Associations among baseline variables, treatment-related factors and health-related quality of life 2 years after breast cancer surgery. Breast Cancer Research and Treatment 2011;28:735-747. DOI: 10.1007/s10549-011-1631-y

31. Vahdaninia M, Omidvari S, Montazeri A. What do predict anxiety and depression in breast cancer patients? A follow-up study. Social Psychiatry and Psychiatric Epidemiology 2010;45: 355-361. DOI: 10.1007/s00127-009-0068-7

32. Vries J, van der Steeg AF, Roukema JA. Trait anxiety determines depressive symptoms and fatigue in women with an abnormality in the breast. British Journal of Health Psychology 2009;14:143-157. DOI: 10.1348/135910708X310200

33. Ganz PA, Desmond KA, Leedham B, Rowland JH, Meyerowitz BE, Belin TR. Quality of life in long-term, disease-free survivors of breast cancer: a follow-up study. Journal of the National Cancer Institute 2002;94:39-49.

34. Hyphantis T, Almyroudi A, Paika V, Degner LF, Carvalho AF, Pavlidis N. Anxiety, depression and defense mechanisms associated with treatment decisional 
preferences and quality of life in nonmetastatic breast cancer: a 1-year prospective study. Psycho-Oncology 2013;22:2470-2477. DOI: 10.1002/pon.3308

35. Rottmann N, Hansen DG, Larsen PV, Nicolaisen A, Flyger H, Johansen C, Hagedoorn M. Dyadic coping within couples dealing with breast cancer: A longitudinal, population-based study. Health Psychology 2015;34:486-495. doi: $10.1037 /$ hea0000218

36. Manne SL, Ostroff J, Winkel G, Grana G, Fox K. Partner unsupportive responses, avoidant coping, and distress among women with early stage breast cancer: patient and partner perspectives. Health Psychology 2005;24:635-641. DOI: 0.1037/02786133.24.6.635

37. Stanton AL, Danoff-Burg S, Huggins ME. The first year after breast cancer diagnosis: hope and coping strategies as predictors of adjustment. Psycho-Oncology 2002;11:93-102. DOI: 10.1002/pon.574

38. Michael YL, Berkman LF, Colditz GA, Holmes MD, Kawachi I. Social networks and health-related quality of life in breast cancer survivors: a prospective study. Journal of Psychosomatic Research 2002;52:285-293. DOI: 10.1016/S00223999(01)00270-7

39. Carver CS, Smith RG, Antoni MH, Petronis VM, Weiss S, Derhagopian RP. Optimistic personality and psychosocial well-being during treatment predict psychosocial well-being among long-term survivors of breast cancer. Health Psychology 2005;24:508-516. DOI: 10.1037/0278-6133.24.5.508

40. van der Steeg AF, De Vries J, Roukema JA. Anxious personality and breast cancer: possible negative impact on quality of life after breast-conserving therapy. World Journal of Surgery 2010;34:1453-1460. DOI: 10.1007/s00268-010-0526-0

41. Den Oudsten BL, De Vries J, van der Steeg AF, Roukema JA, Van Heck GL. Determinants of overall quality of life in women over the first year after surgery for early stage breast cancer. Quality of Life Research 2009;18:1321-1329. DOI: $10.1007 / \mathrm{s} 11136-009-9548-1$

42. Bleiker EM, Pouwer F, van der Ploeg HM, Leer JW, Adèr HJ. Psychological distress two years after diagnosis of breast cancer: frequency and prediction. 
Patient Education and Counseling 2000;40:209-217. DOI: 10.1016/S07383991(99)00085-3

43. Lam WW, Soong I, Yau TK, Wong KY, Tsang J, Yeo W, ... Fielding R. The evolution of psychological distress trajectories in women diagnosed with advanced breast cancer: a longitudinal study. Psycho-Oncology 2013;22:2831-2839. DOI: 10.1002/pon.3361

44. Keyzer-Dekker CM, de Vries J, Mertens MC, Roukema JA, van der Steeg AF. The impact of diagnosis and trait anxiety on psychological distress in women with early stage breast cancer: a prospective study. British Journal of Health Psychology 2014;19:783-794. doi: 10.1111/bjhp.12076

45. Hack TF, Degner LF. Coping responses following breast cancer diagnosis predict psychological adjustment three years later. Psycho-Oncology 2004;13:235-247. DOI: $10.1002 /$ pon.739

46. Henselmans I, Fleer J, Vries J, Baas PC, Sanderman R, Ranchor AV. The adaptive effect of personal control when facing breast cancer: Cognitive and behavioural mediators. Psychology \& Health 2010;25:1023-1040. DOI: 10.1080/08870440902935921

47. Millar K, Purushotham AD, McLatchie E, George WD, Murray GD. A 1-year prospective study of individual variation in distress, and illness perceptions, after treatment for breast cancer. Journal of Psychosomatic Research 2005;58:335-342.

48. Moreira H, Canavarro MC. A longitudinal study about the body image and psychosocial adjustment of breast cancer patients during the course of the disease. European Journal of Oncology Nursing 2010;14:263-270. DOI: 10.1016/j.ejon.2010.04.001

49. Kyranou M, Puntillo K, Dunn LB, Aouizerat BE, Paul SM, Cooper BA, Neuhaus J, West C, Dodd M, Miaskowski C. Predictors of initial levels and trajectories of anxiety in women before and for 6 months after breast cancer surgery. Cancer Nursing 2014;37:406-417. doi: 10.1097/NCC.0000000000000131. 
50. Manne SL, Ostroff JS, Norton TR, Fox K, Goldstein L, Grana G. Cancer-related relationship communication in couples coping with early stage breast cancer. Psycho-Oncology 2006;15:234-247. DOI: 10.1002/pon.941

51. Lam WW, Fielding R. Is self-efficacy a predictor of short-term post-surgical adjustment among Chinese women with breast cancer? Psycho-Oncology 2007;16:651-659.

52. van der Steeg AF, De Vries J, van der Ent FW, Roukema JA. Personality predicts quality of life six months after the diagnosis and treatment of breast disease. Annals of Surgical Oncology 2007;14:678-685. DOI: 10.1245/s10434-006-9175-9

53. Lam WWT, Yeo W, Suen J, MingHo W, Tsang J, Soong I, Yau TK, Wong KY, Sze W K, Ng AWY, Kwong A, Suen D, Fong D, Ho S, Fielding R. Goal adjustment influence on psychological well-being following advanced breast cancer diagnosis. Psycho-Oncology 2015;25:58-65. doi: 10.1002/pon.3871

54. Saboonchi F, Petersson LM, Alexanderson K, Branstrom R, Wennman-Larsen A. Expecting the best and being prepared for the worst: structure, profiles, and 2-year temporal stability of dispositional optimism in women with breast cancer. PsychoOncology 2015; Advanced online publication. doi: 10.1002/pon.4045

55. Nosarti C, Roberts JV, Crayford T, McKenzie K., David AS. Early psychological adjustment in breast cancer patients A prospective study. Journal of Psychosomatic Research 2002;53:1123- 1130.

56. Sears SR, Stanton AL, Danoff-Burg S. The yellow brick road and the emerald city: Benefit finding, positive reappraisal coping and posttraumatic growth in women with early-stage breast cancer. Health Psychology 2003;22:487-497. DOI: 10.1037/0278-6133.22.5.487

57. Rissanen R, Arving C, Ahlgren J, Cernvall M, Nordin K. Cognitive processing in relation to psychological distress in women with breast cancer: a theoretical approach. Psycho-Oncology 2014;23:222-228. DOI: 10.1002/pon.3392

58. Lazarus RS, Folkman S. Stress, appraisal, and coping. Springer Publishing Company; New York; 1984. 
59. Bárez M, Blasco T, Fernández-Castro J, Viladrich C. Perceived control and psychological distress in women with breast cancer: A longitudinal study. Journal of Behavioral Medicine 2009;32:187-196. DOI: 10.1007/s10865-008-9180-5

60. Cousson-Gélie F. Breast cancer, coping and quality of life: A semi-prospective study. European Review of Applied Psychology 2000;3:315-320.

61. Silva SM, Crespo C, Canavarro MC. Pathways for psychological adjustment in breast cancer: A longitudinal study on coping strategies and posttraumatic growth. Psychology \& Health 2012;27:1323-1341. DOI: 10.1080/08870446.2012.676644

62. Mosher CE, Danoff-Burg S. A review of age differences in psychological adjustment to breast cancer. Journal of Psychosocial Oncology 2006;23:101-114. DOI: 10.1300/J077v23n02_07

63. Moreira H, Canavarro MC. Tipo de cirurgia, adaptação psicossocial e imagem corporal no cancro da mama [Type of surgery, psychosocial adjustment and body image in breast cancer]. Psicologia, Saúde \& Doenças 2012;13:169-190.

64. Conversano C, Rotondo A, Lensi E, Vista OD, Arpone F, Reda MA. Optimism and its impact on mental and physical well-being. Clinical Practice \& Epidemiology in Mental Health 2010;6:25-29. DOI: 10.2174/1745017901006010025

65. Reblin M, Uchino BN. Social and emotional support and its implication for health. Current Opinion in Psychiatry 2008;21:201-205. DOI: 10.1097/YCO.0b013e3282f3ad89

66. Adler NE, Page AE. Cancer care for the whole patient: Meeting psychosocial health needs. The National Academies Press: Washington DC; 2008.

67. Bisschop MI, Kriegsman DM, Beekman AT, Deeg DJ. Chronic diseases and depression: The modifying role of psychosocial resources. Social Science \& Medicine 2004;59:721-733. DOI: 10.1016/j.socscimed.2003.11.038

68. Kuijer RG, Ridder DT. Discrepancy in illness-related goals and quality of life in chronically ill patients: the role of self-efficacy. Psychology \& Health 2003;18:313330. DOI: $10.1080 / 0887044031000146815$ 
69. Maddux J. Self-efficacy: The power of believing you can. In Handbook of positive psychology, Snyder CR, Lopez SJ (eds). Oxford University Press: New York, 2002;277-287.

70. Lahey BB. Public health significance of neuroticism. The American Psychologist 2009; 64:241-256. DOI: 10.1037/a0015309

71. Ozer DJ, Benet-Martínez V. Personality and the prediction of consequential outcomes. Annual Review of Psychology 2006;57:401-421.

72. Aldao A. The future of emotion regulation research: capturing context. Perspectives on Psychological Science 2013;8:155-172. DOI: 10.1177/1745691612459518

73. Fledderus M, Bohlmeijer ET, Pieterse ME. Does experiential avoidance mediate the effects of maladaptive coping styles on psychopathology and mental health? Behavior Modification 2010;34:503-519. DOI: 10.1177/0145445510378379

74. Sansone RA, Sansone LA. Rumination: relationships with physical health. Innovations in Clinical Neuroscience 2012;9:29-34.

75. Mitchell AJ. Pooled results from 38 analyses of the accuracy of distress thermometer and other ultra-short methods of detecting cancer-related mood disorder. Journal of Clinical Oncology 2007;25:4670-4681. doi: 10.1200/JCO.2006.10.0438

76. Brandão TB, Matos, PM. Eficácia das intervenções psicológicas em grupo dirigidas a mulheres com cancro da mama: uma revisão sistemática [Efficacy of psychological group interventions for women with breastcancer: A systematic review]. Revista Portuguesa de Saúde Pública 2015;33:98-106. doi: 10.1016/j.rpsp.2015.01.001

77. Brandão TB, Schulz MS, Matos PM. Psychological intervention with couples coping with breast cancer: A systematic review. Psychology \& Health 2014;29:491-516. doi: 10.1080/08870446.2013.859257

78. Ackerman RA, Ledermann T, Kenny DA. Using dyadic analysis in health psychology. The European Health Psychologist 2010;12:18-20. 
79. de Ridder D, Greenen R, Kuijer R, van Middendorp H. Psychological adjustment to chronic disease. Lancet 2008;19:246-255. doi: 10.1016/S0140-6736(08)61078-8

80. Brandão T, Tavares R, Schulz MS, Matos PM. Measuring emotion regulation and emotional expression in women with breast cancer: A systematic review. Clinical Psychology Review 2015;43:114-127. doi: 10.1016/j.cpr.2015.10.002 